\title{
The Effectiveness of Differentiated Teaching Strategy in Developing Reading Comprehension Skills of Fourth Grade Students in the United Arab Emirates
}

\author{
Nisreen A. Ma'youf \\ Al Ain University, United Arab Emirates \\ Ibtehal M. Aburezeq \\ Al Ain University, United Arab Emirates
}

\begin{abstract}
The aim of this study is to investigate the effectiveness of the differentiated teaching strategy in developing reading comprehension skills of fourth grade students in the United Arab Emirates. The study sample consisted of (49) male and female students, who were randomly distributed into an experimental group (23 students), and a control group (26 students). The experimental group was taught using the Differentiated Teaching strategy, and the control group was taught using the traditional method. To conduct the study and answer its questions, the researchers used the quasi-experimental approach and constructed a reading comprehension test. After the completion of the study, the post-test of reading comprehension skills was implemented; scores of the two groups were obtained; and the data were analyzed using the appropriate statistical methods. The results revealed that there were statistically significant differences in the post-test at the four levels (literal, deductive, critical, and creative) and reading skills in general between the scores of the two study groups in favor of the experimental group. This indicates that the Differentiated Teaching strategy had a positive impact on developing students' reading comprehension skills. In light of the results, a number of recommendations were drafted and presented.
\end{abstract}

Index Terms-strategy, differentiated Teaching, reading comprehension skills, fourth grade

\section{INTRODUCTION}

In recent years, there has been a constant flow of knowledge and innovation as a result of the impressive revolution of amazing scientific achievements, which in turn led to great development and progress in various fields of science and other domains of knowledge. One of the major concerns of contemporary education is the upbringing of students and improving their performance in various aspects and developing their attitudes and inclinations for the better and providing them with various concepts and skills which develop their personalities to help them achieve success. Therefore, language acquisition has been at the core of research as a tool of learning and self-expression (Al-Saedi, 2016).

Arabic language has a great value in our culture, and our true religion has urged learning Arabic language. AlTha'alibi - may God Almighty have mercy on him - mentioned that in his saying: "He who loves Almighty God loves His Messenger, may God bless him and grant him peace, and he who loves the Arab Prophet, loves the Arabs, and whoever loves the Prophet and the Arabs loves Arabic language, in which the best book was revealed and whoever loves Arabic is concerned with it, perseveres in it, and spends his energy on it" (Al-Tha'alibi, 2000, P. 29).

Reading is one of the most important language skills used in learning and teaching Arabic, especially for primary school students, and it is one of the basic skills on which the rest of the branches of linguistic activity are built, such as listening, speaking, and writing, and it is also a learning tool throughout school life (Al-Khalifa, 2004).

Recently, reading has received a great attention in many countries of the world, and it has gained a lot of importance in various educational institutions, because of its major and effective role in the educational process. The United Arab Emirates is among the first countries that has shown a clear and noticeable interest in spreading the culture of reading and consolidating it among members of society, especially among students, by launching a series of initiatives, programs and events aimed at raising their knowledge and cultural level. However, the process faced numerous challenges which forced the government to recruit experts who are able to address these challenges and build a living example to be followed as a civilized and social model.

Furthermore, reading is a necessary tool for acquiring culture, knowledge and experience as it works on developing the virtues, values and behaviors desired by the society and individuals. It enhances the individual's self-confidence and educates him on his rights and duties; it also develops in students all the skills of lower and higher thinking and thinking 
out of the box, and instills in them curiosity and in-depth reading. In other words, it is a tool for achieving excellence in all subjects and removing the barrier of time and place for the reader, as he relates to others no matter how far apart the times or distances are between them. The importance of reading also involves developing the emotional side of the learner, by developing the skill of literary appreciation, interaction and harmony with the text. In the hierarchical ladder of linguistic growth, reading represents the third level which includes five domains: (receptive language, expressive language, reading, writing, and the use of spoken and written language in daily life) (Ayoub, 2017).

The purpose of reading is comprehension, with its various skills and this is what language education pivots around in order to optimize comprehension. Jad (2003) pointed out that: "Reading comprehension is the supreme goal of reading which the teacher seeks to achieve and the educational process aims at" (P. 18). Reading without understanding is not reading in its proper sense. Reading comprehension is defined as the process of correct linking between the signs of a word and its meaning, finding the appropriate meaning from the context, understanding and organizing the ideas in the readable content, and remembering these ideas later for the purpose of using them later in present and future activities (Younis et al., 1998).

The learner also exercises a number of mental operations through reading comprehension skills including analysis, conclusion, judgment, criticism, and others. There is no doubt that reading refines individuals' ideas, shows their talents, and highlights their innovations. The rise of man and his culture is related to the style of reading itself, and how it is invested in the reader (Al-Hamid, 2010).

A good reader can comprehend the text and reach the apparent or implicit meaning, near or far, and this makes reading a mental process based on thinking and related to it. Hence, the relationship between good reading and understanding is unquestionable (Ashour \& Al-Hawamdeh, 2003). Realizing the great importance of reading comprehension, the Ninth Scientific Conference (2009) of the Egyptian Society for Reading and Knowledge at Ain Shams University stressed the need to train learners on various reading methods that develop their reading comprehension skills, and make them able to combine reading and thinking at the same time. However, in reality, according to Al-Saedi (2016), students exhibit alarming weakness in reading comprehension, at all academic levels.

The researchers of this study believe that one of the reasons for this weakness is due to the teacher's failure to use educational strategies that suit the abilities, tendencies, and motives of different students. In light of this reality, it is not logical to hold the teacher responsible for the different abilities of the students; rather, the responsibility of the teacher lies in making sure that all students are engaged and immersed in the learning process, and encouraging them to work and learn in their preferred styles (Dajani, 1999).

Based on the foregoing, the researchers find that the possession of reading comprehension skills is affected by the significant differences between the levels of learners in the classroom, and varies according to their abilities, preparations and previous experiences. Reading is a process with mental and cognitive dimensions, by which the reader is able to extract the meanings included in the reading text, understand them, and respond to the ideas contained therein, relying on the combination of his previous experiences and concepts, and the new knowledge in the text, and interact with them intellectually and emotionally. Hence, a trend has emerged in education taking into account this diversity which has been called Diversified Teaching or Differentiated Teaching.

Differentiated Teaching seeks to create an appropriate learning environment for all students in terms of preparations, abilities and previous experiences they have, in addition to the distinct needs, backgrounds and the learning styles they prefer. Likewise, it works to differentiate each of the contents, teaching methods, activities and assessment methods in the selected lessons, in order to achieve the desired teaching goals, advance the level of students' academic achievement, and improve the efficiency of the educational process with the ultimate goal of achieving the mission of total quality in education (Kojk et al., 2008; Attia, 2009).

Differentiated Teaching is an educational method based on diversity in terms of the presence of individual differences between students in the same class. The teacher's reliance on one method of teaching does not necessarily achieve the learning among all students with the same quality and quantity (Al-Laqani \& Al-Jamal, 2003).

The teacher's provision of differentiated Teaching depends on the need to know each student in the class, and on the teacher's choice of appropriate strategies to teach each student, as differentiated teaching takes into account the individual characteristics of the learners and their previous experiences, with the aim of raising the level of all learners (Obeidat \& Abu Al-Sameed, 2007).

In addition, Differentiated Teaching is based on diversification of procedures, processes and tools to achieve a single educational outcome, and this in turn will help the learner to achieve better learning (Attia, 2009). Differentiated Teaching has many forms, including education based on the theory of multiple intelligence; teaching according to learning patterns like the auditory pattern, the visual pattern, the kinesthetic pattern, the sensory pattern, and the verbal pattern. It may also be in the form of cooperative learning based on organizing and distributing tasks according to the interests of the learners. Since the differentiation of education is not limited to a specific field, education may differ in content, processes, product, learning environment, assessment methods and tools, in addition to the use of technology to support differentiated Teaching (Kojk et al., 2008).

The importance of Differentiated Teaching stems from several aspects, most notably of which is that it is based on the principle that education is a right for all, as it takes into account the different types of learners and the different tendencies and interests of students. It raises their level of challenge to learn, increases their level of motivation towards 
education, and develops innovation and creativity among learners, and facilitates integration between the different methods of education (Al-Halisi, 2012). We conclude that Differentiated Teaching is a fertile environment that achieves effective learning in line with the needs of all learners.

Recognizing that importance and in response to its requirements, several conferences dealt with Differentiated Teaching strategy, such as the Twenty-Fourth Annual Conference held in the Kingdom of Bahrain during the period (30-31 March 2010), which recommended activating Differentiated Teaching in schools, and the International Conference on Educators held in the State of Kuwait at Al-Bayan Bilingual School (2010) which pivoted around the difference between Differentiated Teaching and traditional education in terms of content, methods and evaluation with reference to the theory of multiple intelligence. This conference emphasized the importance and effectiveness of Differentiated Teaching (Nasr, 2014).

After reviewing many previous researches and studies that confirmed the impact and effectiveness of Differentiated Teaching, such as the study of Khammas (2017), Nima (2017), Al-Ahmad \& Al-Juhaimi (2015), Nasr (2014), and Bahlool (2013), this study attempts to benefit from the results and recommendations of these studies in teaching reading lessons using the Differentiated Teaching strategy with view of revealing its effectiveness in developing the reading comprehension skills of fourth grade students.

\section{RELATED LITERATURE}

The researchers used both the Flexible Grouping strategy and the Tiered Activities strategy within Differentiated Teaching strategy in the current study, because they are the most appropriate strategies in terms of the possibility of tailoring educational activities in proportion to the students' abilities and needs to achieve the required goals.

\section{A. Here is an Explanation of These Two Strategies}

\section{Flexible Grouping Strategy}

This strategy is similar to the cooperative learning strategy, except that each student in the class is a member of several different groups formed by the teacher in the light of a framework of teaching, learning objectives and the characteristics of students. In this method, the student is allowed to move between groups according to his educational needs, and the place is prepared and organized to provide the appropriate learning resources for each group, in line with both the nature of the content presented and the characteristics of the students. The teacher, in this setting, must follow up the students through roaming and moving between groups, and based on an assessment for each student individually according to his level of achievement (Nasr 2014).

\section{Tiered Activities Strategy}

It is a strategy used when students differ in the cognitive or skill level, and when they learn the same concepts or perform certain skills, and since this difference does not qualify students to start from the same starting point or at one specific level, the teacher must design gradual and different activities in terms of levels so that each student can start with the activity which is commensurate with his level of knowledge or skill, and progresses gradually according to his speed, and under the supervision and guidance of the teacher to achieve the intended level. The more the activity corresponds to the preparations and tendencies of the students, the more motivated they become to complete the activity and move to another level of learning. In this strategy the teacher has to design the activities and place each student in the appropriate activity for his level while continuing to follow up and direct the students (Tomlinson, 2005; Kojk et al., 2008).

\section{B. Differentiated Teaching Procedures}

There are number of steps that must be taken into account when applying Differentiated Teaching, and they are defined by Obeidat \& Abu Al-Sameed (2007), Attia (2009), and Al-Shukairat (2009) as follows:

- Conducting an evaluation process that aims to determine the abilities and skills of each learner before applying the Differentiated Teaching strategy (what does each learner know? What does he need?)

- Classifying the learners into groups according to the commonalities among the members of each group, which were reached in the light of the pre- evaluation results.

- Developing a plan to implement the lesson according to specific educational goals, based on work methods and activities appropriate for the three levels of outstanding, average and weak students, taking into account the diversity of learning goals according to Bloom's levels of knowledge, diversifying teaching methods and strategies according to the interests of learners and diversifying the expected outcomes from learners.

- $\quad$ Selecting the necessary means and tools for learning and the appropriate learning resources.

- Organizing the educational environment in a way that accommodates the requirements of all groups.

- Choosing the educational strategies and methods that suit each learner or group, while introducing the modifications necessary to make the strategy fit this diversity.

- Determining the various tasks and activities to be assigned to the learners to achieve the learning objectives.

- Conducting an evaluation process after implementing the lesson plan to measure learning outcomes, for the purpose of identifying and addressing weaknesses of the learners. 


\section{Reading Comprehension Levels and Skills}

There are many divisions of reading comprehension skills varied according to different perspectives among experts. Some divided them according to the size of the reading unit, while other classified them according to the type and size of the cognitive message implied in the reading text. Others divided them according to level of non-tangible mental processes inferred by their behavioral outcomes, such as literal understanding, interpretive understanding, implications (reading between the lines) and critical understanding (saad, 2006).

Hijazi (2008) also indicated that the goal of determining the levels of reading comprehension skills lies in helping the teacher to prepare reading goals and facilitate attaining them. This can be done by choosing appropriate educational strategies to be used in developing students' ability to understand the reading material, determining students' skills and their ability to comprehend, determining the type of knowledge and experiences that teachers should provide to students to improve their reading comprehension ability, correcting and formulating the appropriate questions of the reading material with view of achieving the results that teachers want students to obtain.

Abdul Bari (2010), Al-Khaza'leh et al. (2011), and Attia (2016) categorized the levels of reading comprehension and the sub-skills they fall under as follows:

1. Literal, direct or superficial understanding level: this represents the student's ability to literally understand the meanings of words, structures, sentences, information and events contained in the read text, through direct understanding and not beyond that.

This level includes the following sub-skills:

- Determine the appropriate meaning of the word from the context.

- Determine two or more different meanings for the word.

- Determine the synonym of the word.

- Determine the opposite word.

- $\quad$ Determine the general central idea of the text.

- Determine the main idea of the text paragraphs.

- Identify sub-ideas and their supporting details in the text.

- Determine the temporal and spatial order of the events of the story.

- Determine the order in order of importance to the ideas contained in a topic or story.

2. The level of deductive or explanatory understanding: This level represents the student's ability to know and understand the implicit meanings that the writer did not declare in the text, by going beyond the direct meanings.

This level includes the following sub-skills:

- $\quad$ Find similarities and differences in the text.

- Interpret cause-and-effect relationships for the events of a topic or story.

- Deduce the writer's purposes and motives.

- Deduce the characteristics of the writer's style of reading.

- Deduce common values and trends in the read text.

- $\quad$ Infer the ideas and meanings implicit in the reading text.

3. The level of critical understanding: This represents the student's ability to make judgments related to the readable text in terms of language, semantics and function, and then evaluate them in terms of their accuracy, quality, and the strength of their impact on the reader, according to exact and appropriate criteria.

This level includes the following sub-skills:

- Distinguish between main ideas and sub-ideas.

- Distinguish between facts and opinions in what is read.

- Distinguish between ideas belonging to and not belonging to the subject being read.

- Distinguish between reasonable and unreasonable ideas.

- Distinguish between a common and an innovative idea.

- $\quad$ Express opinion on the ideas and issues raised in the reading.

- $\quad$ judge the logicality of the ideas and their sequence.

- judge the originality and contemporariness of the content.

- Judge the author's credibility.

4. The level of taste understanding: This sub-skill represents the student's ability to sense the writer's feelings prevailing in the general atmosphere of the text, and his possession of an expressive linguistic style to express them from his point of view, and his ability to elicit the suggestive expressions that the writer aims at and the specific emotional directions that they carry, and to elicit the secrets of beauty in expression, etc. popularized in the text as of trends and values.

This level includes the following sub-skills:

- $\quad$ Arrange the verses according to the strength of the meaning.

- $\quad$ Realize the suggestive significance and the aesthetic value in expressions and words.

- $\quad$ Be aware of the mood and emotional state in the atmosphere of the literary text.

- Realize the interrelationship between the two sides of thought and conscience.

- Determine the appropriateness of the words to the writer's feelings and emotions. 
5. The level of creative understanding: It represents the student's ability to present innovative and new ideas, and to suggest a new intellectual path or direction, whereby the student starts from facts and information that are known to him, while he sees unconventional and new uses for them, or sees distinct relationships between them.

This level includes the following sub-skills:

- Creatively rearrange the events, ideas or characters of the text.

- Suggest alternative solutions to some of the problems mentioned in the text.

- Reach expectations for some events based on certain assumptions.

- Predict the events of the story and plot them before reading it fully.

- Suggest an end to a story or topic, for which an end has not been determined (Abdul Bari, 2010; Al-Khaza'leh et al., 2011; Attia, 2016).

Many studies were conducted dealing with Differentiated Teaching strategy around the world. Khammas (2017) conducted a study on fifth-grade literary students, and the results revealed the superiority of the students who study history using Differentiated Teaching over their peers who study the same subject using the common educational techniques in the achievement test. He concluded that Differentiated Teaching strategy helps students to have selfconfidence and self-reliance, makes the student at the center of the educational process, and makes learning easier and more interesting. Nima (2017) also demonstrated in her study of fifth grade students the effectiveness of Differentiated Teaching strategy in developing reflective thinking skills in teaching social studies. A study by Al-Ahmad \& AlJuhaimi (2015), which was conducted in the biology course for second-year secondary school students, revealed the effectiveness of Differentiated Teaching strategy according to the format model in developing the level of conceptual comprehension, and improving performance in the achievement test as a whole. Nasr (2014) emphasized in her study the effectiveness of Differentiated Teaching in developing reading and writing skills in Arabic language for second graders. Bahlool (2013) emphasized, in his study of ninth grade students in the English language, the effectiveness of Differentiated Teaching strategy in improving students' reading comprehension skills, in addition to many benefits accrued to students in terms of motivation, responsibility and cooperation.

There are also other studies conducted to develop reading comprehension skills by employing different strategies, methods and teaching content. A study conducted by Al-Masry (2017) revealed high effectiveness of an electronic program in developing reading speed and reading comprehension skills among fourth-grade students. Ayoub (2017) showed in her study on second grade students the significant impact of employing active learning strategies in light of the (SCHOOL-BASED TEACHER DEVELOPMENT PROGRAM) in developing the overall performance of reading comprehension skills, including the development of each of its levels, and the absence of differences between male and female students in that. The results of Issa's study (2017) revealed the significant impact of divergent thinking strategies in developing reading comprehension skills in Arabic language for fourth grade female students at each of its levels, but they had no effect on the critical level. Johnson's study (2014) found an effect of cumulative activity and peer relationships on developing reading comprehension, in addition to providing students with social skills. The Pagan \& Seneschal study (2014) conducted on third and fifth grade students, respectively, showed the role of parents participating in the summer reading program in developing students' reading comprehension skills, enhancing their fluency and increasing their vocabulary acquisition.

\section{Purpose of the Study}

The study aimed to identify the effectiveness of the Differentiated Teaching strategy in developing the reading comprehension skills of fourth grade students in the United Arab Emirates, at the levels of literal reading comprehension, inferential reading comprehension, critical reading comprehension, and creative reading comprehension.

\section{E. Significance of the Study}

The importance of the current study from a theoretical perspective is that it adds more information to studies that investigate the effectiveness of Differentiated Teaching in the field of education, and studies that aim to improve students' reading comprehension skills, in addition to enlightening educational experts and teachers with modern strategies such as Differentiated Teaching strategies in teaching Arabic. To improve the educational process, this study also came in response to the UAE's trends in the field of education, which focus on guiding students towards the skill of reading, which develops all aspects of students' knowledge and enriches their linguistic and cultural output.

The importance of this study from a practical perspective is to provide educational material for teachers on how to apply Differentiated Teaching strategy in teaching the Arabic language in general, and reading comprehension skills in particular. It may also draw the attention of curriculum developers to the Differentiated Teaching strategy and its impact on teaching Arabic language skills, which helps in raising the level of achievement among students. It also encourages researchers to conduct more studies to investigate the importance of the Differentiated Teaching in developing reading comprehension skills. Furthermore, the study illustrates the need to empower students to master other subjects at different academic levels as reading is the foundation on which students build their competences. It is hoped that this study will provide researchers in this field with a list of skills needed in the evaluation of reading comprehension and measure students' development.

\section{F. Limits of the Study}


- Place: The study was conducted at "Tawam Model Private School" of the Department of Education and Knowledge in the Emirate of Abu Dhabi.

- Sample: fourth-grade students at Tawam Model Private School.

- Objective limits: reading lessons in the second semester of the Arabic language course for the fourth grade, which are (The Ceiling of Dreams, My Small Pan, and My Scarlet Coat)

- Time limits: The experiment was conducted over a period of five weeks, which included (11) lessons, in the second semester of the academic year 2019-2020.

\section{G. Procedural Definitions}

Differentiated Teaching Strategy is a set of educational procedures concerned with diversifying the teaching strategies practiced in the same educational situation, employing two strategies, namely, flexible groups and gradual activities. The researchers followed these strategies in their experiment of teaching reading comprehension to the students of the 4th grade, taking into account the differences among students' abilities, characteristics and background experience and knowledge, so that all students can catch up with the same learning outcomes effectively.

Reading comprehension skills, which are the group of sub-skills included within the four levels (literal reading comprehension, deductive reading comprehension, critical reading comprehension, and creative reading comprehension), which were prepared by the two researchers for the purpose of the study.

Fourth grade: it is the last grade in the first cycle classes, extending from grade (1-4), and the ages of students range from (9-10 years)

\section{H. Problem of the Study}

Many studies and researches indicated, in their recommendations, the need to work on developing students' reading comprehension skills, such as the Al-Masry study (2017), Ayoub's study (2017), Issa's study (2017), Al-Sedawi's study (2015), and other studies. Also United Arab Emirates has called repeatedly for rooting the culture of reading among members of society, and the UAE Ministry of Education established it basic educational strategy on applying modern educational strategies which are student-focused and making them an effective center in the teaching and learning process, taking into account their differences and in tendencies, abilities and previous experiences. Additionally, there have been frequent complaints of the teachers and parents about the low level of reading performance and skills of students in the first cycle classes. Hence, the researchers had a sense of the problem of the study which encouraged them to explore the effectiveness of the Differentiated Teaching strategy in developing the reading comprehension skills of fourth grade students in the United Arab Emirates.

Accordingly, the problem of this study is summarized in the following question:

Are there statistically significant differences at the level of confidence $(\mathrm{a} \leq 0.05)$ between the average scores of the experimental group students and the those of the control group students in the post-test of reading comprehension skills of the four levels (literal, deductive, critical, and creative), which are supposed to be the outcome of the teaching strategy employed in the teaching process?

\section{STUDY METHOD AND PROCEDURES}

\section{A. Study Methodology}

The researchers used the quasi-experimental approach in the design of the experimental and control groups to implement the experiment and achieve its goals, because it is the appropriate approaches to the current study. The experiment should measure the correlation coefficient between the independent and dependent variables (Al-Agha \& Al-Ustad, 2003).

\section{B. The Population and Sample of the Study}

The population and sample of the study consisted of (49) male and female students, (23) male and female students in the experimental group, and (26) male and female students in the control group, from the fourth grade students at "Tawam Model Private School" affiliated to the Department of Education and Knowledge. The researchers chose the school intentionally, given the cooperative attitude shown by the school administration, in terms of facilitating the study procedures. There were three sections in the school for the fourth grade (A, B, C), so section (B) was chosen randomly to be the experimental group, and Section (A) was chosen randomly to be the control group.

\section{Tool of the Study}

For achieving the study objective of identifying the effectiveness of the Differentiated Teaching strategy in developing the reading comprehension skills of fourth grade students, the researchers prepared the study tool which consisted of a list of reading comprehension skills comprising the four main levels: the literal level, the deductive level, the critical level, and the creative level. In addition, a list of fifteen behavioral indicators which fall under these levels was prepared. 
In order to ensure the validity of the list of reading comprehension skills, it was presented to a panel of specialized professors in the field of curriculum and instruction. The researchers also developed the pre and post-tests for evaluation.

\section{Reading Comprehension Skills Tests}

After reviewing the educational literature and previous studies that dealt with reading comprehension tests, the researchers prepared the pre and post tests, which included two reading texts, selected from outside the content of the textbook, in order to avoid the transmission of the effect of training and remembrance, which affects the results of the study.

Each test was in the form of multiple-choice questions, so that each of the test items measures a behavioral indicator, based on the list of reading comprehension skills, which were represented by four main levels (literal reading comprehension, inferential reading comprehension, critical reading comprehension, and creative reading comprehension). The behavioral indicators were (15) indicators, thus the number of test items are (15) items, and four alternatives were given to each item, only one of which is correct for the purposes of presenting it to a panel of arbitrators.

\section{Validity of the Test}

To ensure the apparent validity of the test, the researchers presented it in its initial form to a panel of (10) arbitrators, to express their observations about the test and its paragraphs, to find out the suitability of the two texts to the level of the fourth grade and the extent to which the specific question represents the behavioral indicator that it measures in addition to the formulation of test questions in terms of the integrity of the structure and linguistic form, and the appropriateness of the alternatives used for each question, and to recommend the required deletion, addition or modification of what they deem appropriate. Based on the opinions of the arbitrators, modifications and changes were made to the language of some questions by correcting some vocabulary and expressions, deleting some alternatives, and replacing them with more appropriate ones to reach the final form of the test.

\section{Consistency of the Test}

To ensure the consistency of the test, it was applied to a pilot sample that consisted of (25) fourth-grade male and female students, who were randomly selected from the "Al-Hamdania Al-Kubra Private School" which is affiliated to the Department of Education and Knowledge.

The pilot test was conducted on (15/1/2020), and the reliability coefficient was calculated by Cronbach's alpha as shown in Table No. 1.

TABLE 1

The VAlues Of THE CONSISTENCy COEFFICIENTS For THE FouR LEVELS OF READING COMPREHENSION SKILLS TEST

\begin{tabular}{|c|c|c|}
\hline Level & Number of Questions & Consistency Value \\
\hline Literal understanding & 5 & 0.734 \\
\hline Deductive understanding & 4 & 0.711 \\
\hline Critical understanding & 2 & 0.758 \\
\hline Creative understanding & 4 & 0.657 \\
\hline All Levels & 15 & 0.863 \\
\hline
\end{tabular}

It is clear from Table No. (1) that the consistency coefficient of the levels as a whole is $(0.863)$, while the consistency of the four levels of the test ranged between (0.758) as a maximum, and (0.657) as a minimum, and this indicates that the test has a good and acceptable degree of consistency, as Cronbach's alpha consistency coefficient ranges between (1-0), and the closer its value is to (1), the greater the consistency value is, and the closer it is to (0), the lower the consistency value is. The acceptable value on Cronbach's alpha scale is (0.6) for the research purposes, according to the scale of Liyin Shen (2011) and Deliu (2014), and this is suitable for applying the test to the study sample.

For the purposes of implementing the study, the researchers prepared lesson plans as follows:

\section{Lesson Plans}

After the two researchers were informed and guided by previous studies and educational literature on the Differentiated Teaching strategy and the teachers' supervisor of Arabic language subject for the fourth grade, the lesson plans were prepared for the three targeted lessons (The Ceiling of Dreams, My Small Pan, My Scarlet Coat) from the Arabic Language book, Part Two, assigned for the fourth grade in the United Arab Emirates. To ensure the validity of the lesson plans, the researcher presented them to a panel of specialized professors for guidance.

\section{Equivalence of the Two Study Groups}

To ensure that the experimental and control groups were equal in reading comprehension skills, the test was applied to both groups before implementing the study experiment, and the arithmetic averages and standard deviations of the scores were calculated in both the experimental and control groups, and a t-test was applied on two independent samples. The T. test was used in the pre-test of the combined reading comprehension skills to identify the difference between the average scores of the two study groups. Table No. (2) illustrates this. 
TABLE 2

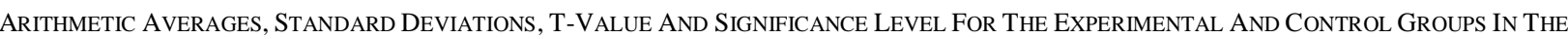
PRE-TEST OF COMBINED READING COMPREHENSION SKILLS

\begin{tabular}{|c|c|c|c|c|c|c|}
\hline Skills & Group & Number & Mean & $\begin{array}{c}\text { Standard } \\
\text { Deviation }\end{array}$ & T-value & Significance \\
\cline { 1 - 5 } Experimental & 23 & 9.83 & 2.87 & 0.542 & 0.590 & Insignificant \\
\hline Control & 26 & 10.23 & 2.23 & & & \\
\hline
\end{tabular}

Table No. (2) shows that the value of (T) equals (0.542), which is not statistically significant at the significance level (0.05), which indicates that there are no statistically significant differences between the average of the experimental group and the average of the control group, in the pre-test of the combined reading comprehension skills, where the average scores of students for the experimental group reached (9.83), and for the control group (10.23), which are close to each other, which confirms that there are no differences between the arithmetic averages of both groups. Thus, the result confirms that the two groups were equivalent before starting the application of the study.

\section{E. Study Variables}

The current study was limited to the following variables:

The independent variable: the teaching methods, namely, differentiated Teaching strategy, and the usual way.

Dependent variable: reading comprehension skills.

\section{F. Statistical Analysis}

To answer the study questions, the researcher used Cronbach's alpha coefficient, Arithmetic averages, standard deviations, and Independent sample T. test.

\section{STUDY RESULTS AND DisCUSSION}

The study question: "Are there any statistically significant differences at the level of confidence $(\mathrm{a} \leq 0.05)$ between the average scores of the experimental group students and the average scores of the control group students in the posttest of reading comprehension skills at the four levels (literal, deductive, critical, and creative) which are attributed to using the Differentiated Teaching strategy and the usual method?

To answer this question, the arithmetic means and standard deviations of the grades of fourth grade students in both the experimental and control groups were extracted, and an independent sample T.test was used in the post-test of reading comprehension skills at the four levels (literal, deductive, and critical) and creative) in the component skills and the overall average to know the difference between the average scores of the two study groups. Table No. (3) shows this.

TABLE 3

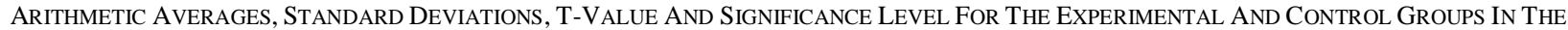
POST-TEST OF READING COMPREHENSION SKILLS

\begin{tabular}{|c|c|c|c|c|c|c|c|}
\hline Skills & Group & Number & Mean & $\begin{array}{l}\text { Standard } \\
\text { Deviation }\end{array}$ & T-value & $\begin{array}{c}\text { Significance } \\
\text { Value }\end{array}$ & $\begin{array}{l}\text { Level of } \\
\text { Sig. }\end{array}$ \\
\hline \multirow{2}{*}{$\begin{array}{c}\text { Literal } \\
\text { understanding }\end{array}$} & Experimental & 23 & 4.39 & 0.58 & \multirow[t]{2}{*}{6.076} & \multirow[t]{2}{*}{0.000} & \multirow[t]{2}{*}{ Significant } \\
\hline & Control & 26 & 3.04 & 0.92 & & & \\
\hline \multirow{2}{*}{$\begin{array}{c}\text { Deductive } \\
\text { Understanding }\end{array}$} & Experimental & 23 & 3.87 & 0.34 & \multirow[t]{2}{*}{5.277} & \multirow[t]{2}{*}{0.000} & \multirow[t]{2}{*}{ Significant } \\
\hline & Control & 26 & 2.92 & 0.80 & & & \\
\hline \multirow{2}{*}{$\begin{array}{c}\text { Critical } \\
\text { understanding } \\
\end{array}$} & Experimental & 23 & 4.26 & 0.54 & \multirow[t]{2}{*}{5.928} & \multirow[t]{2}{*}{0.000} & \multirow[t]{2}{*}{ Significant } \\
\hline & Control & 26 & 2.81 & 1.06 & & & \\
\hline \multirow{2}{*}{$\begin{array}{c}\text { Creative } \\
\text { Understanding }\end{array}$} & Experimental & 23 & 3.65 & 0.65 & 4.582 & \multirow[t]{2}{*}{0.000} & \multirow[t]{2}{*}{ Significant } \\
\hline & Control & 26 & 2.62 & 0.90 & & & \\
\hline \multirow[t]{2}{*}{ Overall Skills } & Experimental & 23 & 16.35 & 1.82 & \multirow[t]{2}{*}{7.270} & \multirow[t]{2}{*}{0.000} & \multirow[t]{2}{*}{ Significant } \\
\hline & Control & 26 & 11.38 & 2.79 & & & \\
\hline
\end{tabular}

It is clear from Table No. (3) that the arithmetic mean of the scores of the experimental group students in the post-test of reading comprehension skills at the four levels (literal, deductive, critical, and creative) and the overall skills are greater than the arithmetic mean of the scores of the students of the control group, and that the calculated " $t$ " value is statistically significant at the confidence level of (0.05) attributed to the application of the Differentiated Teaching strategy.

This result can be explained by the fact that the Differentiated Teaching strategy employed the two implementation techniques (flexible groups, and gradual activities), which were applied in this study to enhance reading comprehension skills at the levels of (literal, deductive, critical, and creative). Moreover, the strategy was effective as it moved students from the position of the passive recipient in the process of learning Arabic language subjects, to the position of the active participant, taking into account the level of their abilities and experience. This has contributed to providing sufficient opportunities for students to discuss and participate in voicing their ideas in order to achieve the desired goals. Therefore, it stimulated students' motivation to learn, raised their level of challenge, and gave them more selfconfidence and self-esteem. At the same time, carrying out tasks in cooperative groups developed their reading 
comprehension process in addition to the preparation and presentation of educational material for targeted reading lessons, including the relevant activities and tasks. Gradual levels of difficulty and complexity suit the level of each student within the three levels of students in the class. It had a role in developing reading comprehension skills, and a positive impact in interacting in the various activities and tasks required from the students, by contributing to a greater response and learning of the required skills, and giving equal opportunities for all students to participate in problem solving.

This strategy provided the students with the opportunity to learn at their own pace, formed new skills, and helped low-achieving students create educational situations that would enable them to be self-reliant in acquiring skills easily and smoothly.

Moreover, continuous feedback helped to activate the learning process and increase its effectiveness as it enabled the students to verify the result of their learning, whether it was going in the right direction, or if it needed to be modified, which led to the students' rectification of their own mistakes and maintaining the correct responses in addition to the involvement in the learning process with enthusiasm and responsiveness. In general, the strategy enhanced the participation of the students effectively leading to better understanding of the reading text. The result of the current study conforms to the results of a group of studies that dealt with the impact of the Differentiated Teaching strategy, such as the Khammas (2017), the Nima (2017), the Al-Ahmad \& Al-Juhaimi (2015), the Nasr (2014), and the Bahlool (2013), which emphasized the effectiveness of the Differentiated Teaching strategy.

This is consistent with what Kojk et al. (2008) indicated in that differentiated Teaching helps students understand and form different meanings, as they are able to use knowledge and employ it in many educational and life situations that they may go through. It also allows students to take responsibility for their own learning through the process of peer teaching and learning and the practice of cooperative learning. This result is supported by what Koeze (2007) indicated that differentiated classes contribute to removing boredom and frustration that may accompany the learning processes, as teachers organize lessons to meet the levels of readiness of their students. The practice of differentiation also builds strongly on brain research, which asserts that the human brain functions by paying attention to meaningful information.

\section{RECOMMENDATIONS}

In light of the findings of this study, the two researchers recommend the following:

1. Employing the Differentiated Teaching strategy in teaching fourth grade students.

2. The designers of the Arabic language curricula should take into account the different levels of students, when designing exercises for reading comprehension lessons.

3. Supporting Arabic language curricula and enriching them with various activities that help develop the reading comprehension skills of fourth grade students.

4. Training students on the method of working in flexible and cooperative groups in reading lessons to enhance the acquisition of the reading comprehension skills.

5. Holding workshops and training courses for Arabic language teachers on applying the Differentiated Teaching strategy.

6. Studying the effectiveness of the Differentiated Teaching in teaching Arabic, and in other subjects as well, and at different educational stages, and measuring its impact on other skills such as listening, speaking or writing skills.

7. Conducting more studies on the effect of the Differentiated Teaching strategy on developing students' reading comprehension skills.

\section{REFERENCES}

[1] Abdul Bari, Maher Shaaban. (2010). Reading comprehension strategies: theoretical foundations and practical applications. Amman: Dar Al Masirah.

[2] Al-Agha, Ihsan \& Al-Ustad, Mahmoud. (2003). Introduction to educational research design, 3rd edition. Gaza: Al-Rantisi Press for Printing and Publishing.

[3] Al-Ahmad, Nidal \& Al-Juhaimi, Amal. (2015). The effectiveness of the differentiated Teaching strategy according to the FORMAT model in developing conceptual comprehension in biology for the second grade of secondary in Riyadh. Research presented to the Excellence in Teaching and Learning Science and Mathematics Conference, entitled: "STEM Orientation". King Saud University, Riyadh May 7-5, 2015.

[4] Al-Halisi, Maaidh bin Hassan. (2012). The effect of using the differentiated Teaching strategy on academic achievement in the English language course for sixth grade students. Unpublished Master's Thesis, Umm Al-Qura University, Makkah, Saudi Arabia.

[5] Al-Hamid, Hassan bin Ahmed. (2010). The effectiveness of a story-based program in developing some creative reading skills for third-grade intermediate students. Unpublished Master's Thesis, Umm Al-Qura University, Mecca, Saudi Arabia.

[6] Al-Khalifa, Hassan Jaafar. (2004). Classes in teaching Arabic (primary, intermediate, secondary). Riyadh: Al-Rushd Library.

[7] Al-Khaza'leh, Muhammad \& Al-Sukhni, Hussein \& Al-Shaksi, Abdullah \& Al-Shobaki, Assaf. (2011). Classroom management and educational outcomes. Jordan: Dar Safaa for Publishing and Distribution.

[8] Al-Laqani, Ahmed Hussein \& Al-Jamal, Ali Ahmed. (2003). A dictionary of educational terms defined in curricula and teaching methods. Cairo: The world of books. 
[9] Al-Masry, Hala Ismail. (2017). The Effectiveness of an Electronic Program to Develop the Skills of Speed and Reading Comprehension among the Fourth-Grade Girls in Gaza. Unpublished Master's Thesis, the Islamic University of Gaza, Gaza, Palestine.

[10] Al-Saedi, Wajdi Muhammad. (2016). Evaluation of learning activities in My Beautiful Language course in light of the reading comprehension skills needed for sixth graders. Unpublished Master's Thesis, Umm Al-Qura University, Mecca, Saudi Arabia.

[11] Al-Sedawi, Khaled Yassin. (2015). The effect of using the "Talal Al-Qamar" strategy on developing the reading comprehension skills of fourth grade female students. Published Master's Thesis, the Islamic University of Gaza, Gaza, Palestine.

[12] Al-Shukairat, Mahmoud. (2009). Teaching Strategies and Assessment: Essays in Teaching Development. Amman: Dar AlFurqan.

[13] Al-Tha'alibi, Abi Mansour Abdul-Malik bin Muhammad bin Ismail. (2000). Philology and the secrets of Arabic (edited by Yassin Al-Ayoubi), 2nd ed. Beirut: Modern Library.

[14] Ashour, Rateb \& Hawamdeh, Muhammad. (2003). Methods of teaching Arabic language between theory and practice. Jordan: Dar Al-Maysara.

[15] Attia, Mohsen Ali. (2009). Comprehensive quality and new in teaching. Amman: Dar Safaa.

[16] Attia, Mohsen Ali. (2016). Metacognitive strategies in reading comprehension. Amman: Dar Al-Mahraj for publishing and distribution.

[17] Ayoub, Nidaa Nizar. (2017). The effect of employing active learning strategies in the light of the (SCHOOL-BASED TEACHER DEVELOPMENT PROGRAM) program in developing the reading comprehension skills of second-grade students. Unpublished Master's Thesis, the Islamic University of Gaza, Gaza, Palestine.

[18] Bahlool, A. (2013). The effect of differentiated instruction strategy on developing ninth graders' English reading comprehension skill at Gaza UNRWA school. Unpublished Master's Thesis, Islamic University Gaza, Gaza, Palestine.

[19] Dajani, M. (1999). The Language Learning Styles of Palestinian Foreign Language Learners at the $10^{\text {th }}$ Grade. Unpublished Master's Thesis, Al-Quds University, Al-Quds, Palestine.

[20] Deliu, Fadel. (2014). Validity and reliability standards in quantitative and qualitative research. Journal of Social Sciences, (19), 92-83.

[21] Egyptian Association for Reading and Knowledge. (2009). The Ninth Scientific Conference on Teaching Reading Books in the Arab World between Readability and Direction. Cairo: Ain Shams University.

[22] Hijazi, Ayman Youssef. (2008). The effectiveness of using metacognitive strategies in developing reading comprehension skills and reading tendencies among sixth graders in Palestine. Unpublished Master's Thesis, Ain Shams University, Cairo, Egypt.

[23] Issa, conscience Ramadan. (2017). The effect of using divergent thinking strategies in developing the reading comprehension skills of fourth grade female students. Unpublished Master's Thesis, Islamic University of Gaza, Gaza, Palestine.

[24] Jad, Mohamed Lotfy. (2003). The effectiveness of a proposed strategy in developing some reading comprehension skills for the second preparatory grade students. Reading and Knowledge Magazine, (22), 47-17.

[25] Johnson, K. (2014). The Cumulative Effect of Hyperactivity and Peer Relationships on Reading Comprehension. Journal of Education and Training Studies, 2(1), 98-102.

[26] Khammas, Falah tune. (2018). The effectiveness of the use of differentiated Teaching in the achievement of history among the literary fifth grade students. Journal of the College of Basic Education for Educational and Human Sciences, University of Babylon, (37), 383-363.

[27] Koeze, P. (2007). Differentiated Instruction: The Effect On Student Achievement In An Elementary School. Published Thesis EdD, Eastern Michigan University, Michigan, U.S.A.

[28] Kojk, Kawthar \& Sayed, Magda \& Khader, Salah al-Din \& Faramawy, Faramawy \& Ayyad, Ahmed \& Ahmed, Aliyah \& Fayed, Bushra. (2008). Diversifying teaching in the classroom A teacher's guide to improving teaching and learning methods in schools in the Arab world. Beirut: UNESCO Regional Office for Education in the Arab World.

[29] Liyin shen, M.ASCE ; Yuzhe Wu ; and Xiaoling Zhang, Ph.D. (2011). key assessment indicators for the sustainability of infrastructure projects. Journal of Construction Engineering and Management, June 2011, pp: 441-451.

[30] Nasr, Maha Salama. (2014). The effectiveness of using the differentiated Teaching strategy in developing the reading and writing skills of second grade students in the Arabic language course. Unpublished Master's Thesis, the Islamic University of Gaza, Gaza, Palestine.

[31] Nima, Sherihan Mohamed Seddik. (2017). The effectiveness of differentiated Teaching in teaching social studies on developing some reflective thinking skills for fifth grade students. Journal of the College of Education Port Said University, (22), 985-959.

[32] Obeidat, Thuqan \& Abu Al-Sameed, Suhaila. (2007). Teaching strategies in the twenty-first century - a guide for the teacher and educational supervisor. Amman: Dar Al-Fikr.

[33] Pagan, S., \& Seneschal, M. (2014). Involving Parents as Ummer Book Reading Program to Promote Reading Comprehension, in Fluency, and Vocabulary in Grade 3 and Grade 5 Children. Canadian Journal of Education, 37(2), 1-31.

[34] Saad, Murad Ali. (2006). Weakness in reading and learning styles. Cairo: The world of books.

[35] Tomlinson, Carol. (2005). The differentiated classroom responding to the needs of all students in the classroom (translation of Dhahran Al Ahli Schools). Dammam: Educational Book House (original publication date 1999).

[36] Younis, Fathi \& El Naga, Mahmoud \& Madkour, Ali. (1998). The basics of teaching Arabic and Islamic education. Cairo: House of Culture.

Nisreen A. Mayouf holds B. A. in Education/ Arabic \& Islamic Teacher from Al Ain University in 2017, and an M. A. of Education Arabic Language Curricula \& Instruction from the same University in 2020. She worked as a teacher in the field of Arabic Education for Elementary school in United Arab Emirates for one year. 
Ibtehal Mahmoud Aburezeq is the Vice President of Development and Follow up and Dean of Student Affairs at Al Ain University in the United Arab Emirates. She holds a B. A. in Arabic Language Literature, M.A. in Curriculum \& Instruction from University of Jordan, and a Ph. D. in Curriculum \& Instruction from University of Washington, USA.

Prior to joining Al Ain University, Prof. Aburezeq worked at University of Washington in Seattle and at Hashemite University in Jordan. Her research interests concentrate on teaching methods and techniques and engaging instructional technology in teaching. Her work has appeared in different national and international refereed educational journals and conferences. In 2014, she received the Distinguished Researcher Award among faculty members at Al Ain University. In addition, she is a reviewer of research projects and papers in several Journals.

Prof. Aburezeq held several administrative positions such as the Dean of Scientific Research and Graduate Studies and the Dean of College of Education, Humanities, and Social Sciences. 